\title{
Macroscopic and Microscopic Analysis of the Tongue of the Greater Cane Rat (Thryonomys Swinderianus, Temminck)
}

\author{
Olumayowa Olawumi Igado, ${ }^{1}$ Adenrele Olalekan Adebayo, ${ }^{2}$ Collins Chika Oriji, ${ }^{1}$ Oluwasanmi Olayinka Aina, ${ }^{1}$ Bankole \\ Olusiji Oke ${ }^{1}$ \\ 'Department of Veterinary Anatomy, Faculty of Veterinary Medicine, University of Ibadan, Nigeria \\ ${ }^{2}$ Department of Veterinary Anatomy, College of Veterinary Medicine, Federal University of Abeokuta, Ogun State, Nigeria
}

Disclose and conflicts of interest: none to be declared by all authors

\begin{abstract}
Introduction: the tongue (glossus) is an essential organ, involved in prehension, grooming and digestion in animals. The increase in awareness of the economic importance of the greater cane rat as a viable source of protein in some climes, makes it imperative to study its anatomy. This study assessed glossal gross morphometry and histology of nine captive-reared adult male GCR.
\end{abstract}

Materials and methods: the mean body weight was $1.969 \pm 0.37 \mathrm{~kg}$, mean age $16.56 \pm 5.13$ months, mean head weight $252 \pm 36.89 \mathrm{~g}$, while weight and relative tongue weight were $2.88 \pm 0.53 \mathrm{~g}$ and $0.15 \pm 0.03 \%$ respectively. The tongues were removed and gross linear measurements were carried out. Tongues were also processed for histology using hematoxylin and eosin, and Masson's trichrome stains.

Results: in animals above $2 \mathrm{~kg}$, measured morphometric parameters were found to proportionately increase with the animal weights. Examination of the oral cavity showed that the number of the hard palate ridges had no relationship with the age or size of the animal. Histologically, the tongue was covered with keratinized stratified squamous epithelium on both surfaces, studded with four basic papillae types and few submucosa glands similar to what obtains in ruminants. On the dorsal surface of the tongue, groups of stratified squamous epithelium formed whorls round a central connective tissue. Lingual salivary glands were observed.

Conclusion: these results may find application in improving the nutritional efficiency that will enhance the domestication/ commercialization of this economically viable rodent.

Key words: Greater cane rat; Glosso-metry; Histology; Tongue.

\section{Introduction}

The greater cane rat - Thryonomys swinderianus, Temminck (GCR), is one of the wild herbivorous rodent species that have drawn the attention of many farmers for domestication in recent years. It is one of two species of cane rats, a small family of hystricognath rodents, popular in sub-Sahara Africa. ${ }^{1}$ In the wild, they have the tendency to live in plantations, feeding on agricultural crops and for which reason they are labelled as agricultural pests. ${ }^{2}$ They are, however, popular for their high meat quality, which makes them a rich food source. They are currently undergoing domestication for commercialisation and are sometimes referred to as micro-livestock. ${ }^{3}$

The tongue (glossus, lingue) is an essential muscular sense organ that that is involved in prehension, taste and manipulation of food in most species. ${ }^{4,5}$ In addition to these primary functions, it is involved with grooming, lapping and making of sounds in some other species. ${ }^{6}$ Clinically, the tongue has also been found to be useful in assessing the health status of an animal as it shows some changes in appearance in cases of ill health, poisoning and a number of other pathological conditions. It is an elongated structure that has an apex, a body and a root. By its location at the floor of the mouth and between the rami of the mandible, the tongue is capable of precise and vigorous movement., 4

With increased awareness of its economic importance and the on-going domestication drive of the GCR, there has been an upsurge in the amount of literature detailing its anatomy especially in the area of reproductive biology, ${ }^{8,9,10}$ skull, craniofacial and ocular anatomy ${ }^{11,12}$ and some aspects of the salivary glands. ${ }^{13,14}$ While the structure of the tongue has been extensively studied in a number of domestic ${ }^{4,15}$ and wild mammals, ${ }^{16,17}$ there is very little data on the tongue of this wild rodent. This work therefore provides baseline gross and histological information on the lingua of the GCR. 


\section{Materials and Methods}

All procedures for handling the animals followed the guide for the care and use of animals, Faculty of Veterinary Medicine, University of Ibadan, Nigeria and the National Institute of Health, USA. Ethical approval was obtained from the Animal Ethical Committee, Faculty of Veterinary Medicine, University of Ibadan, ethical code no: ethics 03/14/04.

Nine clinically healthy adult male GCR were obtained from the Grasscutter domestication Unit, Federal University of Agriculture, Abeokuta, Nigeria. The ages ranged from 18 to 24 months. Individual animal weight was determined using a digital weighing scale (Electronic Kitchen Scale, Camry ${ }^{\circledR}$ EK5350) and recorded in kilograms. Animals were euthanised using ketamine $\mathrm{HCl}$ administered intramuscularly, at a dose rate of $45 \mathrm{mg} / \mathrm{kg}$. After ascertaining that there was cessation of respiration and no response to tactile stimulation, the tongues were removed as described by Igado $^{15}$ and weighed (in grams) immediately after removal with a digital weighing scale having a sensitivity of $1 \times 10^{-3}$ grams (Microwa swiss balance ${ }^{\circledR}$, Mettler-Toledo, Switzerland). The weights were recorded in grams. Linear morphometrics of the tongue were determined with the aid of a digital vernier caliper (Neiko ${ }^{\circledR}$, sensitivity of $0.01 \mathrm{~mm}$ ), and recorded in millimeters.

The following gross parameters were determined on each animal (1 - 10 are glossal parameters, while $11-14$ are general oral morphology):

1. Weight of tongue (TW): determined with the aid of a digital weighing balance and recorded in grams. Attaching muscles were removed as much as possible from each tongue. This was done uniformly for all specimens.

2. Length of tongue (TMaL): this was measured as the distance from the root of the tongue to the apex/tip.

3. Thickness of the tongue at the root (TThR): measured along the dorso-ventral plane at the root of the tongue.

4. Thickness of the tongue at the body (mid-length) (TThB): measured along the dorso- ventral plane at the body of the tongue.

5. Thickness of the tongue at the torus (TThT): measured along the dorso-ventral plane at the torus of the tongue.

6. Thickness of the tongue at the apex (TThAp): measured along the dorso-ventral plane at the apex of the tongue.

7. Width of tongue at the root (TWiR): the distance between the two lateral aspects of the tongue, measured at the root.

8. Width of the tongue at the body (mid-length) (TWiB): the distance between the two lateral aspects of the tongue, measured at the region of the body of tongue.

9. Width of the tongue at the torus (TWiT): the distance between the two lateral aspects of the tongue, measured at the region of the torus of tongue.

10. Width of tongue at the apex (TWiAp): the distance between the two lateral aspects of the tongue, measured at the apex of the tongue.

11. Maximum length of the hard palate (MaL): measured from the most rostral aspect of the hard palate, at the alveoli of the first incisor, to the most caudal aspect where it becomes the soft palate.

12. Width of the hard palate at the commissures of the lips (WCM): width of the hard palate, measured from one lateral aspect to the other, at the region of the commissures of the lips.

13. Width of the hard palate at the anterior region (WAH): width of the hard palate, measured from one lateral aspect to the other, from one upper canine to the other upper canine.

14. Palatine ridges (Ri): number of ridges on the hard palate

\section{Histology samples}

The tongue tissues were prepared routinely for histological staining (Haematoxylin and Eosin and Masson's Trichrome stains) according to previously documented report by Avwioro et al. ${ }^{18}$ Briefly, the tissues were dehydrated in ascending grades of alcohol, cleared in xylene, and impregnated in molten paraffin wax using an automatic tissue processor. They were thereafter sectioned with microtome at $5 \mu \mathrm{m}$. The sections were floated on water in a water bath at $45^{\circ} \mathrm{C}$ and then picked by frosted-end slides, which were fixed on a hotplate for about thirty minutes, and thereafter stained with the Haematoxylin and counterstained with Eosin.

Statistical analysis: All data obtained were analysed with Graphpad prism, version 5, and level of significance was at $\mathrm{p}<0.05$.

\section{Results}

\section{Gross Morphometrics}

Gross morphometric results were presented as mean \pm standard deviation (Table I). 
Table 1. Linear morphometrics of the tongue and hard palate of the greater cane rat

\begin{tabular}{|c|c|c|}
\hline $\mathbf{S} / \mathbf{N}$ & Parameters (unit) & Values $(n=9)$ \\
\hline 1. & Relative tongue weight (\%) & $0.15 \pm 0.03$ \\
\hline 2. & Tongue weight (grams) & $2.88 \pm 0.53$ \\
\hline 3. & Tongue Length (cm) & $4.10 \pm 0.39$ \\
\hline 4. & Thickness of the Tongue at the Root $(\mathrm{cm})$ & $.47 \pm 0.22$ \\
\hline 5. & Thickness of the Tongue at the Body $(\mathrm{cm})$ & $1.01 \pm 0.29$ \\
\hline 6. & Thickness of the Tongue at the Torus $(\mathrm{cm})$ & $1.33 \pm 0.36$ \\
\hline 7. & Thickness of the Tongue at the Apex $(\mathrm{cm})$ & $0.38 \pm 0.25$ \\
\hline 8. & Tongue Width at the Root $(\mathrm{cm})$ & $1.20 \pm 0.19$ \\
\hline 9. & Tongue Width at the Body $(\mathrm{cm})$ & $0.94 \pm 0.24$ \\
\hline 10. & Tongue Width at the Torus $(\mathrm{cm})$ & $1.53 \pm 0.17$ \\
\hline 11. & Tongue Width at the Apex $(\mathrm{cm})$ & $0.64 \pm 0.21$ \\
\hline 12. & Maximum length of the hard palate $(\mathrm{cm})$ & $2.50 \pm 0.00$ \\
\hline 13. & $\begin{array}{l}\text { Width of the hard palate at the } \\
\text { commissures of the mouth }(\mathrm{cm})\end{array}$ & $1.43 \pm 0.17$ \\
\hline 14. & $\begin{array}{l}\text { Width of the hard palate at the anterior } \\
\text { region }(\mathrm{cm})\end{array}$ & $0.93 \pm 0.17$ \\
\hline 15. & Number of palatine ridges & $5.78 \pm 1.09$ \\
\hline
\end{tabular}

All the parameters measured in the greater cane rat, weighing above $2 \mathrm{~kg}$ were found to be higher with increase in weight.

The mean weight of the GCR was $1.97 \pm 0.37 \mathrm{~kg}$, at an average age of $16.56 \pm 5.13$ months. The average weight of the heads and mean weight of the tongue were $252 \pm 36.89 \mathrm{~g}$ and

$2.88 \pm 0.53 \mathrm{~g}$ respectively. The relative tongue weight was $0.15 \pm 0.03 \%$.

Grossly, the dorsal part of the root had numerous large conical papillae, extending as far as the lateral aspects (Fig. 1).

The shape of the hard palate was narrow rostrally, wider in the middle and narrower caudally, similar to the general shape of the tongue, which was thickest and widest at the torus (Fig. 2). The number of ridges on the hard palate ranged from 4 to 8 . One animal (11.1 $\%)$ had 4 ridges, $1(11.1 \%)$ had eight ridges, 2 (22.2\%) had five ridges, while 5 (55.5\%) had 6 ridges. It is worth mentioning however, that the animal with 4 ridges was not the youngest, neither was it the smallest in size.

\section{Tongue Histology}

Haematoxylin and Eosin Stain: The mucosa on the dorsal and ventral aspects of the tongue was keratinised stratified squamous epithelium (Fig. 3AB). Numerous mucosal pegs were present on the dorsal surface. The mucosal surface on the ventral aspect had foldings, unlike the dorsal surface which had projections (lingual papillae) (Fig. 3A-C). The dorsal surface had an abundance of papillae (mostly filiform, but includes fungiform, foliate and circumvallate). The height of these papillae varied from $0.2 \mu \mathrm{m}$ to $0.7 \mu \mathrm{m}$. Taste buds were observed on circumvallate, fungiform and the foliate papillae (Fig. 3D).

The muscular layer of the tongue was traversed majorly by skeletal muscles; smooth muscles (longitudinal and circular) were also observed. The muscular layer was typically very thick (Fig. 3).

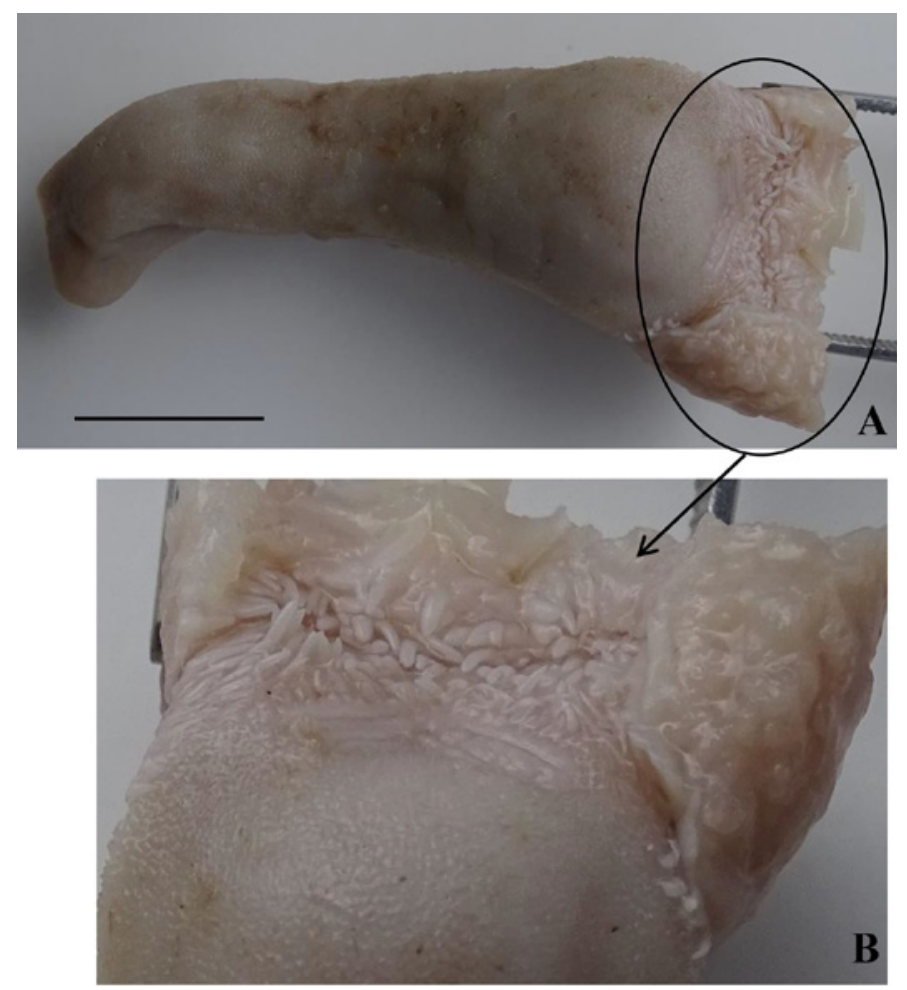

Figure 1. Dorsal view of the tongue of the GCR. Panel B is magnification of circled area in $A$, showing the papillae at root of tongue. Note the conical papillae of the tongue, prominent in the caudal region highlighted. Scale bar $1 \mathrm{~cm}$.

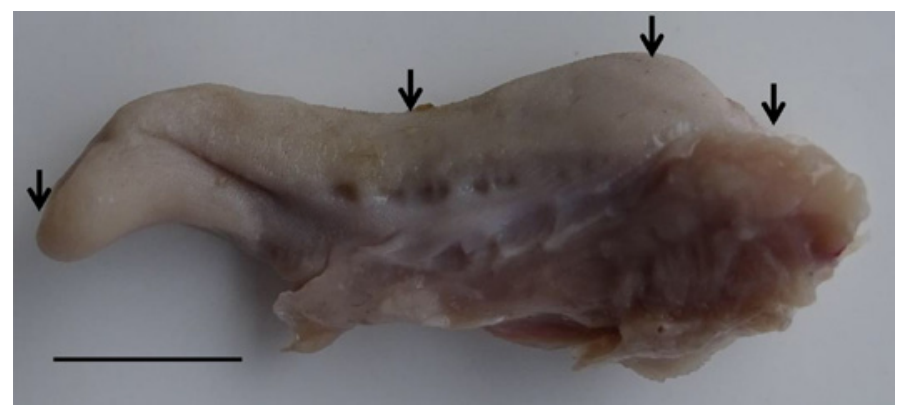

Figure 2. Lateral view of the tongue of the GCR. Arrows from left to right indicate the apex, body, torus and root. Scale bar $1 \mathrm{~cm}$.

There were numerous lingual salivary glands (serous and mucus) almost confined to the caudal region of the tongue while submucosal glands were scattered all-over the tip and middle of the tongue. Mucous glands were more numerous than serous glands. The salivary glands exhibit distinct lobulation emphasized by thick connective tissue investment. These connective tissue were more abundant around the lobules of the mucous glands compared to that of the serous glands (Fig. 4A-C). Serous demilunes were observed on the serous glands (Fig. 5). 

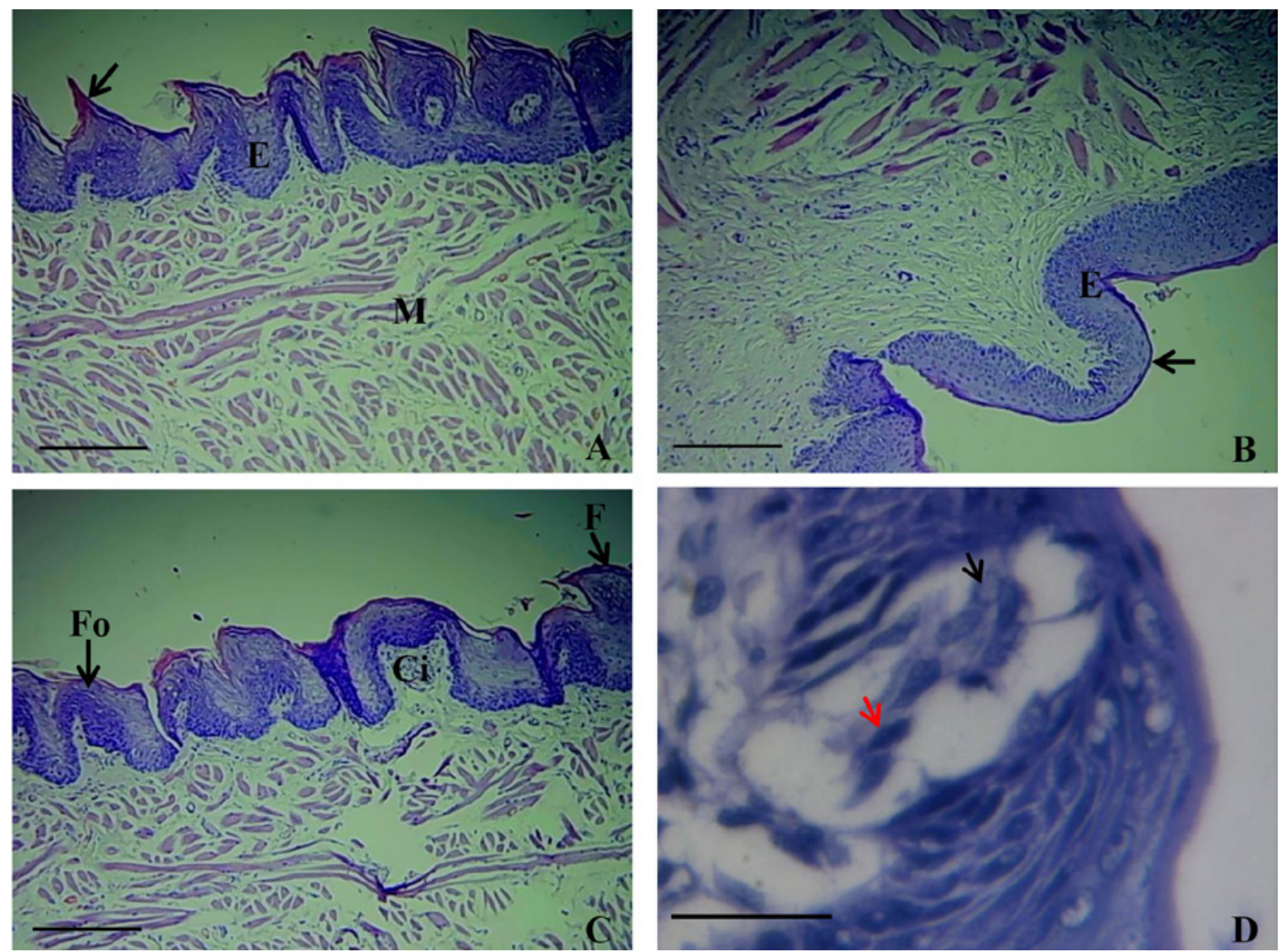

Figure 3. Micrographs of the tongue of the GCR (H\&E). Panel A is the dorsal surface, 'B' is the ventral surface. Note the keratin layer in A and B (arrows), stratified squamous epithelium (E), the thick muscular layer (M), the filiform papillae (F), circumvallate (Ci) and foliate (Fo) in panel C. 'D' is the taste bud in circumvallate papillae, note the supporting cell nucleus (Black arrow) and the sensory cell nucleus (red arrow). Scale bar $200 \mu \mathrm{m}$ (A - C) and $30 \mu \mathrm{m}$ (D).
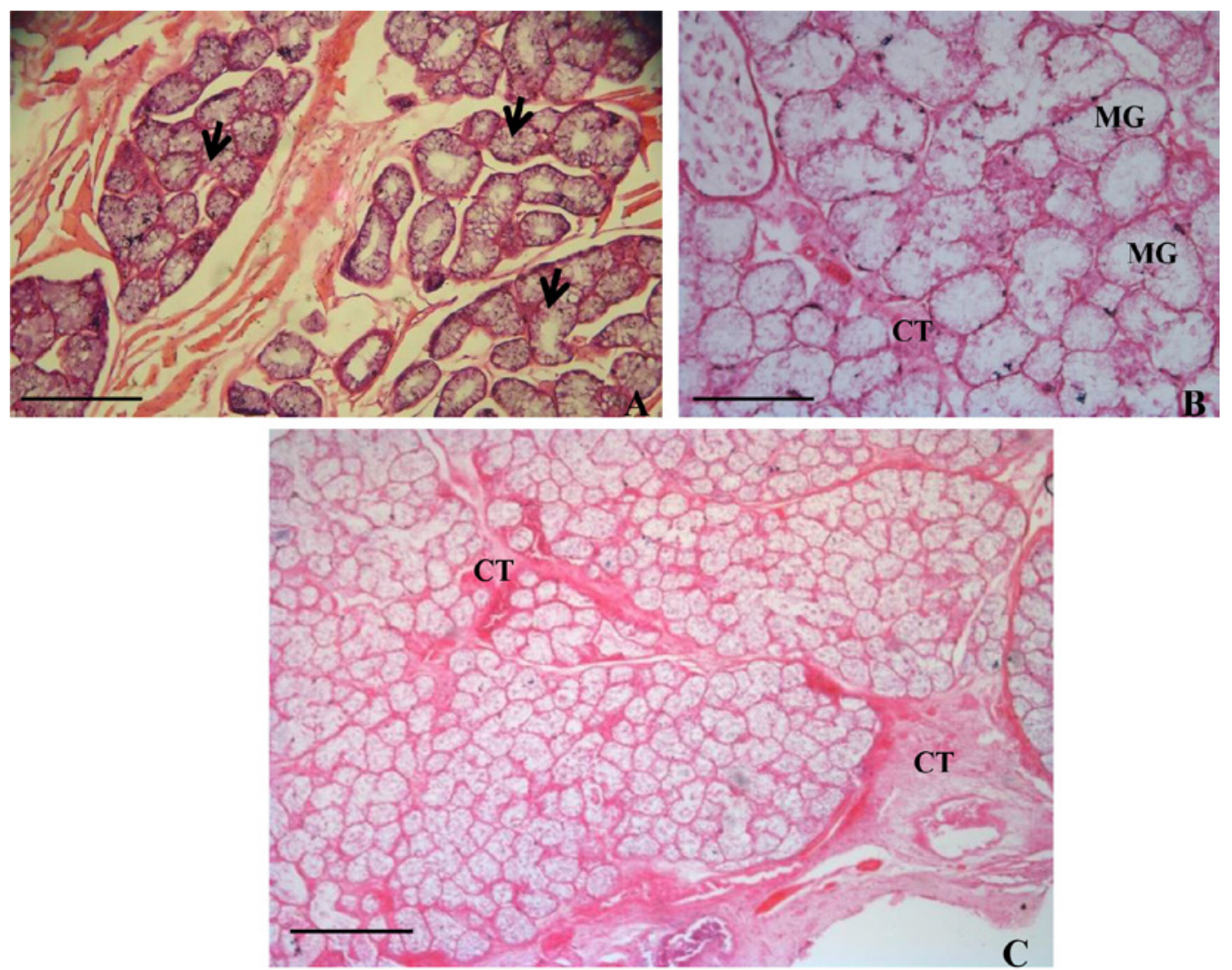

Figure 4. The tongue of the GCR (H\&E). 'A' is serous salivary glands while ' $B$ ' is mucous salivary glands. $C$ is a lower magnification of ' $B$ '. Mucous glands were more numerous than serous glands. Note the abundance of connective tissue (CT) in ' $C$ '. Arrows in ' $A$ ' indicate serous salivary glands in the muscular layer. $C T=$ connective tissue, $M G=$ mucous glands. Scale bar $250 \mu \mathrm{m}$. 


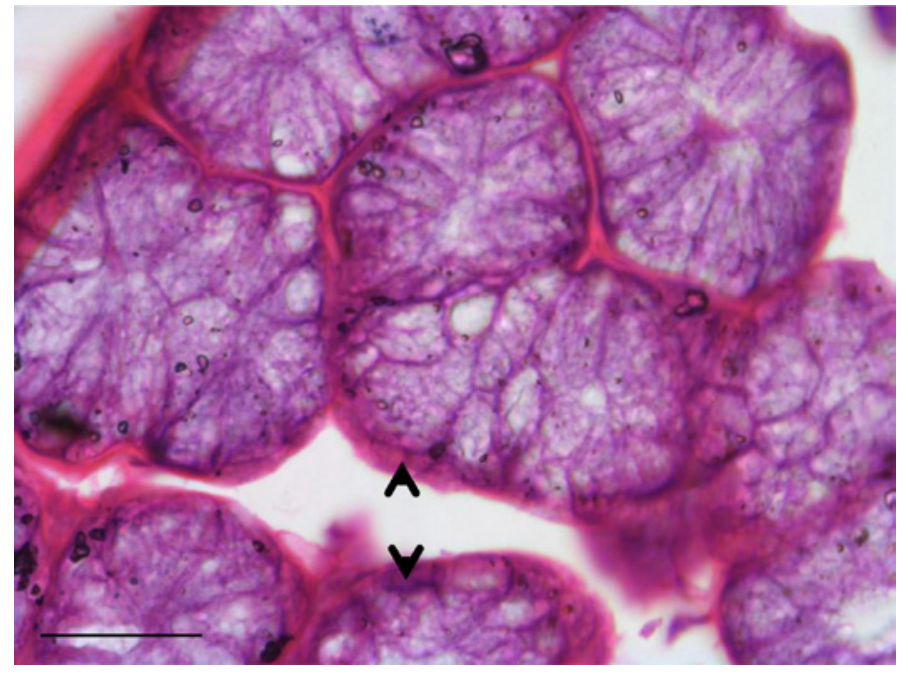

Figure 5. Serous glands of the tongue of the GCR (H\&E). Arrow-heads indicate demilunes. Note the thick connective tissue (arrows). Scale bar $30 \mu \mathrm{m}$.

Masson's Trichrome (MT) Stain: In the dorsocaudal aspect of the tongue, thick stratified squamous epithelium accentuated by cellular margins was observed. Groups of stratified squamous epithelium formed whorls round a central connective tissue
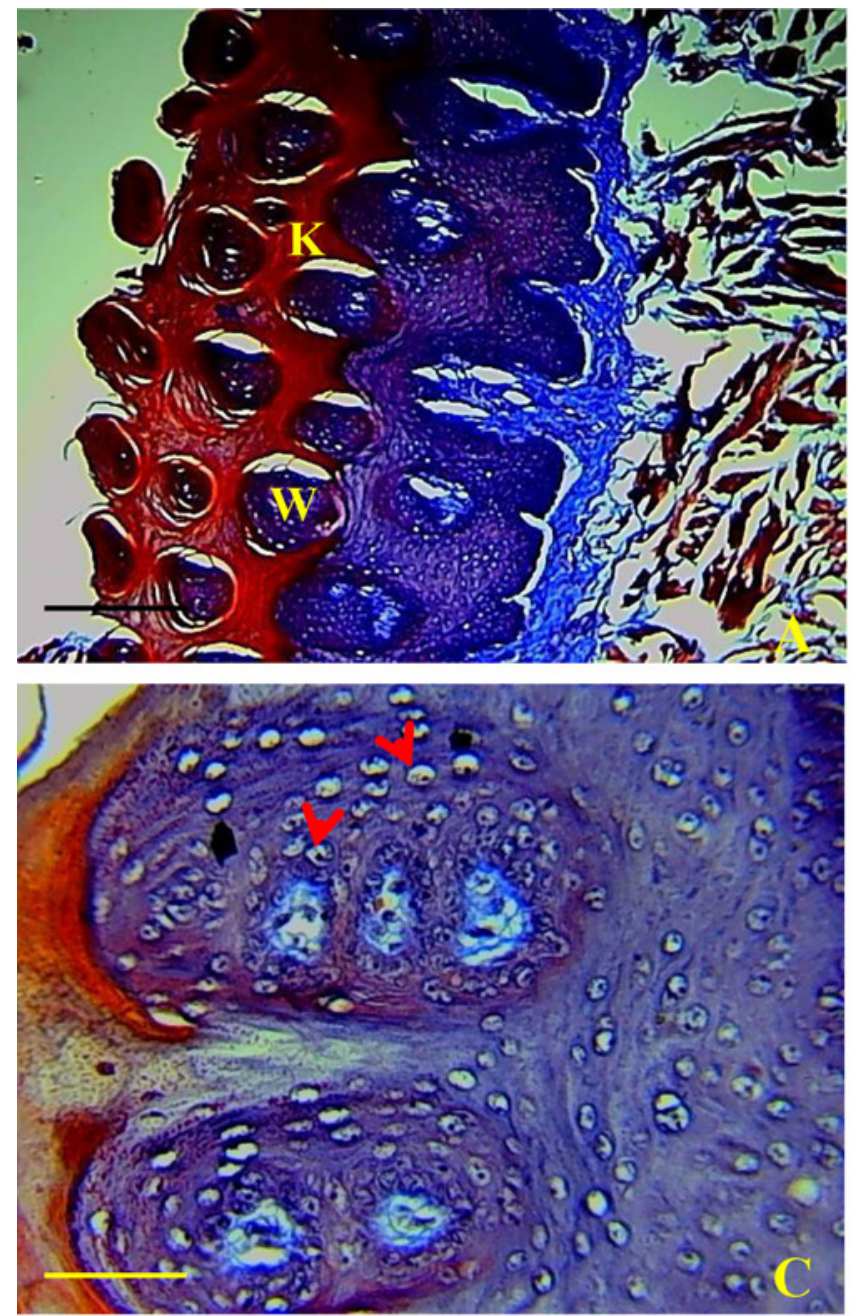

Figure 6. Micrographs of the dorso-caudal aspect of the GCR tongue (Masson's Trichrome stain). Note the whorls (W) formed by stratified squamous cells around the connective tissue, the keratin layer (K), the submucosal connective tissue (CT) and the hypertrophied squamous cells in C (red arrows), Connective tissue are stained blue in all the micrographs. Scale bar - $200 \mu \mathrm{m}(\mathrm{A}) ; 50 \mu \mathrm{m}$ (B, C and D). 

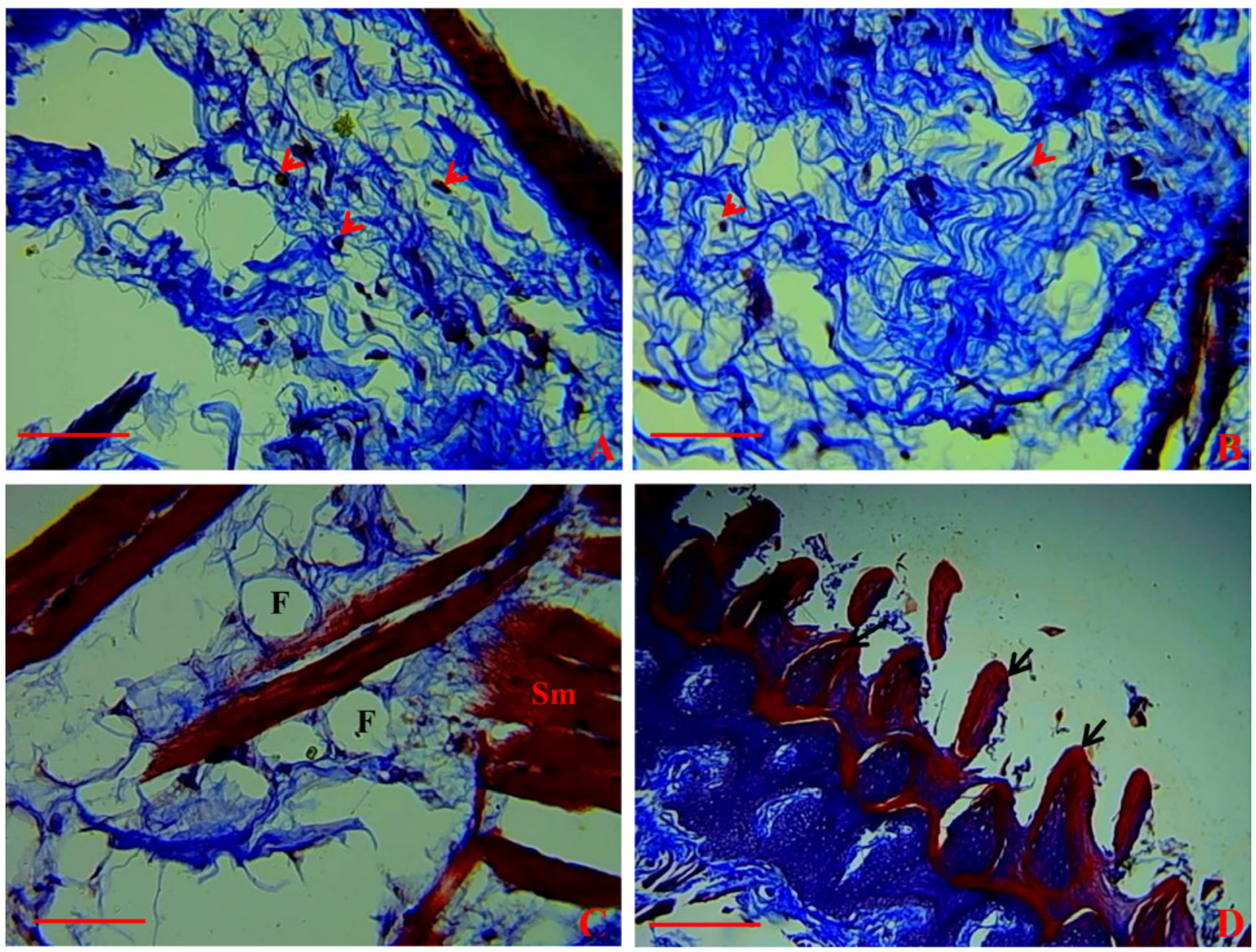

Figure 7. Micrographs of the GCR tongue (Masson's Trichrome stain), showing irregularly arranged connective tissue (blue). Note the fibrocytes present (red arrows in $A$ and B), adipose tissues (F) and the skeletal muscles (Sm) with their nuclei (in C). Fig. D shows the filiform papillae having a club-shaped appearance as it projects caudad (black arrows). Scale bar - $200 \mu \mathrm{m}$ (A, B and D); $50 \mu \mathrm{m}$ (C).

\section{Discussion}

The structure of the tongue, which to a large extent reveals its role in feeding and feed utilization, varies in different animal species. ${ }^{4,5}$ With the current increase in the captive-rearing and domestication of the GCR, baseline information on the structure of its tongue will not only aid the understanding of feed utilization and digestion but also impact on the early diagnosis of some pathological conditions of the GCR in captivity. ${ }^{14}$ To this end, this work provides the gross, morphometrical and histological information on the tongue of the GCR. It has been reported that there are regional variations in the structure of the tongue which reflects the different uses of the tongue in different species. ${ }^{19}$ In a previous work on the Nigeria local $\operatorname{dog},{ }^{15}$ there was a relationship between the weight of the tongue and body weight up to a certain age. This work showed similar pattern in the GCR (though there is no evidence of lapping up of fluid in GCR). Here we observed that, animals above $2 \mathrm{~kg}$ showed similar glossal morphometry which may indicate a cessation of glossal growth when certain body weight is attained in the GCR. However, further works on the development of the tongue with age and body weight in the cane rat are on-going. In the same vein, the relative tongue weight of $0.15 \%$ observed in the GCR is considerably lower than $0.48 \%$ reported in pigs $^{20}, 0.33 \%$ in dogs ${ }^{15} 0.63 \%$ in hedgehogs, and $3.15 \%$ in rats. ${ }^{21}$ But, the presence of the torus in the GCR tongue is consistent with previous reports in other mammals., ${ }^{4,15,22}$

The shape and number of ridges on the hard palate has been reported to be different even among species of the same herbivorous class. ${ }^{16}$ While the hard palate width is uniform in goats, it is said to be wide rostrally and caudally, but narrower at the level of the commissures in the sheep, ox and deer. ${ }^{16}$ The shape of the hard palate observed in the GCR, though an herbivore, is similar to what we saw in the bat. ${ }^{17}$ Also, the number of hard palate ridges seen in GCR had a wider range (four to eight) compared to seven to ten reported in cats; 15 reported in ruminants, 20 in pigs, ${ }^{22}$ eight in the $\operatorname{dog}^{15}$ and seven to eight in bat. ${ }^{17}$ This difference in the shape and numbers of hard palate ridges seen in GCR, may not be unconnected with the unique manner by which it holds the grass while feeding. ${ }^{23}$

Histologically, the GCR tongue was covered by keratinized stratified squamous epithelium typical of tongues in herbivorous mammals. ${ }^{4}$ However, the 
degree of keratinisation observed in the GCR is less compared with that reported in other herbivores but similar to what obtained in the cat. ${ }^{24}$ According to Addo $^{1}$ and Opara, ${ }^{23}$ GCRs are wasteful feeders, feeding only on the nutritive succulent inner nodes of the grass and leaving behind scattered pieces on the ground. This may explain, in a way, the relatively lesser degree of epithelial keratinisation observed in the GCR tongue. However, although the keratin layer of the GCR tongue was not as thick as in ruminants, the architectural arrangement in the GCR looked more complex, due to the whorls. This feature in addition to the mucosal pegs probably makes it as strong as the tongue in other herbivores.

Moreover, while the lamina propriae submucosa and its associated glands as well as the extensive skeletal muscular layer of GCR tongue are typical of what obtains in other mammals, the delineating connective tissue of the salivary glands in the tongue appear to be thicker than that seen in other herbivores..$^{19,24}$ The reason for this is yet to be fully understood.

In conclusion, the anatomical information on the tongue of GCR provided in this study may find application in the nutritional management and disease diagnosis in this rodent as well as serve as a basis for phylogenic interspecies comparison.

\section{References}

1. Addo, P.G.; Awumbila, B.; Awotwi E.; and Ankrah NA. Reproductive characteristics of the female grasscutter (Thryonomys swinderianus) and formulation of colony breeding strategies. Livest Res Rural Dev. 2007;15(1):1-3.

2. Merwe $M$. Tooth succession in the greater can rat Thryonomys swinderianus. J Zool. 200AD;251:541-545.

3. Karikari, P.K.; and Nyameasem JK. Productive Performance and Carcass Characteristics of Captive Grasscutters. World Appl Sci J. 2009;6(4):557-563.

4. Dyce K.M.; Sack W.O.; Wensing C.J.G. Textbook of Veterinary Anatomy. 3rd Edition, Saunders.; 2002.

5. Iwasaki S. Evolution of the structure and function of the vertebrate tongue. J Anat. 2002;201(1):1-13.

6. Pastor, J.F.; Barbosa, M.; and De Paz FJ. Morphological study of the lingual papillae of the giant panda (Ailuropoda melanoleuca) by scanning electron microscopy. J Anat. 2008;212(2):99 - 105.

7. Drake, R.L.; Vogl, W.; and Mitchell AWM. Gray's Anatomy for Students. Philadelphia, Pennsylvania: Elsevier. Pp. 989 - 995. ISBN 978-0-8089-2306-0.; 2005.

8. Adebayo, A.O.; Oke, B.O.; and Akinloye AK. The Gross Morphometry and Histology of the Male Accessory Sex Glands in the Greater Cane Rat (Thryonomys swinderianus, Temminck). J.Vet. Anat.,. J Vet Anat. 2009;2(2):41-51.

9. Adebayo, A.O.; Akinloye, A.K.; Olukole, S.G.; Oyeyemi, M.O.; Taiwo, V.O.; Ihunwo, A.O.; and Oke BO. Gross, Histological and Ultrastructural Features of the Bulbourethral Gland in the Greater Cane Rat (Thryonomys swinderianus). Anat Histol Embryol. 2014;44(1):59-65. 10. Adebayo, A.O.; Akinloye, A.K.; Ihunwo, A.O.; Taiwo, V.O.; and Oke BO. Ultrastructural studies of Acrosomal formation in the testis of male greater cane rat (Thryonomys swinderianus). J Microscroscopy Ultrastruct. 2017; doi.org/10.

11. Olude, M. A.; Mustapha, O. A.; Sonubi, A. C.; Falade, T. E.; Ogunbunmi, T. K.; Adebayo, A. O.; and Akinloye AK. Morphometric Studies of the Skull of the Greater Cane Rat (Thryonomys swinderianus Temminck). Niger Vet J. 2014;35(3):1026-1037.

12. Igado, O. O.; Adebayo, A. O.; Oriji, C. C. and Oke BO. Craniofacial and Ocular Morphometrics of the Male Greater Cane Rat
(Thryonomys swinderianus). Niger Vet J. 2016;37(March):54-63. 13. Igbokwe, C.O.; Neba, P.C.; and Bello UM. Comparative histology and histochemistry of major salivary glands in the giant pouchedrats (Cricetomys gambianus) and greater cane rats (Thryonomys swinderianus). Indian J Anim Res. 2015;49(4):451-460.

14. Igbokwe CO. Ultrastructure of the Parotid Salivary Gland in the Greater Cane Rats (Thryonomys swinderianus). J Microscroscopy Ultrastruct. 2017; doi.org/10.

15. Igado 00. Gross morphometric study of the eyeball and tongue of the Nigerian local dog.

Ital J Anat Embryol. 2011;116(1):104-110.

16. Sreeranjini, A. R.; Rajani, C. V.; and Ashok N. Gross anatomical studies on the hard palate, tongue and buccal floor in sambar deer (Cervus unicolor). Tamilnadu J Vet Anim Sci,. 2010;6:151-156.

17. Igado OO, Omobowale TO, Ajadi RA, Nottidge HO. Gross morphometric studies on the tongue, buccal cavity and hard palate of the fruit bat (eidolon helvum). J Vet Med Ser C Anat Histol Embryol. 2015;44(4):283-287.

18. Avwioro, O.G.; Iyiola, S.; and Aghoghovwia B. Histological and biochemical Markers of the Liver of Wistar rats on subchronic oral administration of green tea. N Am J Med Sci. 2010;2(8):376-380.

19. Junqueira, L.C.; and Carneiro J. Basic Histology Text and Atlas. 10th Edition. Lange Medical Books McGraw-Hill.; 2003.

20. Olopade JO, Igado OO, Nwafor Cl, Alamu AO, Onwuka SK. Some aspects of the craniofacial indices and macro neurometrics of the Nigerian local pig (Sus scrofa). Ital J Anat Embryol. 2011;116(1):38-44. 21. Adeniyi, P.A.O.; Owolabi, J.O.; Ghazal, O.K.; Fatunke, I.D.; Oyowopo, A.O.; Omotosho, G.O.; Oyesomi, T.O.; Jimoh, O.R.; and Caxton-Martins EA. A comparative study of tongue and dentition in rats, bats and hedgehogs. Int J Biomed Heal Sc,. 2010;6(3):137-141.

22. Getty R. The Anatomy of the Domestic Animals, Vol $1 \& 2,5^{\text {th }}$ Edn. Philadelphia, PA: Saunders Company.; 1975.

23. Opara MN. The grasscutter I: A livestock of tomorrow. Res J For. 2010;4:119-135.

24. Bacha, W.J.; and Bacha LM. Colour Atlas of Veterinary Histology, $3^{\text {rd }}$ Edition. Wiley- Blackwell, UK.; 2012.
Received: November 11, 2019

Accepted: January 12, 2020
Corresponding author

Olumayowa Olawumi Igado

mayowaigado@yahoo.com 